\title{
Uma Iniciativa para Apoiar e Empoderar Alunas de Ensino Técnico e de Graduação em Computação
}

\author{
Kecia A. M. Ferreira, Glívia A. R. Barbosa, Sílvia C. de Albuquerque \\ Departamento de Computação \\ Centro Federal de Educação Tecnológica de Minas Gerais (CEFET-MG) \\ Av. Amazonas, 7675 - Belo Horizonte, MG - Brazil \\ \{kecia,gliva, silviacalmon\} defetmg.br
}

\begin{abstract}
This paper presents a project proposed by female teachers from an educational institution that has two technical courses and a graduation course in Computing. We present an experience report of the actions in the context of the project that have been directed to the female students in order to encourage and support them to complete their courses, as well as encourage them in relation to the job market. As a result of the project, we expect to create and consolidate a network of mutual support between the female students, as well as a group to advise those students, with systematic activities supervised by the teachers.
\end{abstract}

Resumo. Este artigo apresenta um projeto criado por professoras em uma instituição de ensino que possui dois cursos técnicos e uma graduação na área de Computação. É descrito um relato de experiências a partir das ações no âmbito do projeto direcionadas a essas alunas para incentivá-las e apoiá-las a concluir seus cursos e encorajá-las para o mercado de trabalho. Como resultado do projeto, espera-se criar e consolidar uma rede de apoio mútuo entre as alunas desses cursos, bem como um grupo de orientação a elas, com atividades sistemáticas supervisionadas pelas professoras.

\section{Introdução}

Computação é uma área em que apenas uma pequena parcela da comunidade é de mulheres (Cohoon e Asprey, 2006). A quantidade de mulheres que ingressam em cursos da área tem se reduzido cada vez mais (Santos, 2018; Beaubouef e Zhang, 2011).

Várias são as razões apontadas para baixa representatividade feminina na área, entre elas, a pouca ou a falta de interação de meninas com tecnologias, pouco incentivo dado às meninas para buscarem carreiras em Computação e as dificuldades enfrentadas por mulheres no mercado de trabalho, tais como discriminação, salários baixos comparados aos dos homens e empecilhos socioculturais para progressão na carreira (Maia, 2016)(Matsu, 2017). Essa é uma questão que tem ganhando cada vez mais atenção. Investigá-la, bem como propor iniciativas para mudar esse cenário, pode contribuir para promover a igualdade de gênero, um dos objetivos da Organização da Nações Unidas (ONU) até 2023 para mudar o mundo (ONU, 2015). 
Dentre os vários desafios que uma mulher encontra para a escolha de uma carreira em Computação, destacam-se dois: (i) o preconceito que geralmente cerca a área, sendo ela considerada pelo senso comum uma carreira masculina; e (ii) os preconceitos e a falta de referência feminina que a aluna encontra durante os cursos de Computação, podendo-a levar a desânimo e, em muitos casos, à desistência da área (Maia, 2016)(Matsu, 2017)(Sales, et al. 2014)(Santos, 2018).

Com isso, dois problemas principais são identificados: (i) é preciso aproximar as alunas dos ensinos básico e médio da área de Computação e minimizar o mito de que Computação é uma área masculina, para que elas passem a se sentir fortalecidas a optarem por carreiras nessa área, se assim desejarem; e (ii) é preciso apoiar e incentivar alunas que cursam Computação, para favorecê-las a concluírem seus cursos e ingressarem no mercado de trabalho (Sales, et al. 2014)(Santos, 2018).

Este artigo apresenta o projeto Elas.net, criado por um grupo de professoras do Departamento de Computação do Centro Federal de Educação Tecnológica de Minas Gerais (CEFET-MG). O departamento possui dois cursos técnicos e um curso de graduação na área de Computação, totalizando cerca de 100 alunas. Antes de 2018, não havia ainda na instituição uma iniciativa voltada para as mulheres na Computação.

\section{Relato de Experiência}

O projeto descrito neste artigo teve início em março de 2018. Esta seção relata a experiência de três atividades das principais atividades realizadas no projeto até então.

\subsection{Encontro das Professoras e Alunas do Departamento}

O encontro de professoras e alunas do departamento contou com mais de 52 participantes e teve por objetivos: (1) apresentar o projeto às alunas; (2) propiciar que as alunas se conhecessem; (3) identificar as demandas e principais necessidades de apoio das alunas.

A coordenadora do projeto fez uma apresentação sobre algumas das principais mulheres que têm atuado na Computação ao longo dos anos. A seguir, foi apresentada a ideia da criação do projeto, explicando o contexto, a motivação e seu objetivo principal: apoio e incentivo às alunas dos cursos de Computação da instituição.

Na sequência, foi aberto um espaço para depoimentos e sugestões das alunas e professoras presentes. A coordenadora do projeto iniciou com um depoimento sobre a sua própria trajetória, as dificuldades e desafios que enfrentou no mercado de trabalho e que enfrenta na área acadêmica. Duas das professoras presentes também deram os seus depoimentos, destacando que também enfrentam diversas situações desafiadoras como mulheres na Computação. Diante desses depoimentos, as alunas parecem ter se sentido mais à vontade para expressarem suas percepções e dificuldades nos cursos. Os seguintes relatos principais foram trazidos pelas alunas:

- elas se sentem inseguras e intimidadas quando necessitam elucidar dúvidas com professores e colegas do sexo masculino, relatando que se sentem mais à vontade quando encontram uma colega com quem possam esclarecer suas dúvidas; 
- elas têm a percepção que seus colegas do sexo masculino não confiam na capacidade técnica delas, mesmo quando elas têm um rendimento escolar superior aos deles;

- as alunas vivenciam piadas e comentários machistas por parte de colegas e também por parte de professores do sexo masculino;

- algumas das alunas que já atuam no mercado trabalho relatam já terem passado por situações de constrangimento de cunho sexual por parte de colegas do sexo masculino;

Os principais resultados deste encontro foram:

- as alunas consideraram a iniciativa do projeto relevante;

- elas apontaram que sentiam necessidade de orientação sobre o mercado de trabalho, o que motivou a segunda atividade no âmbito deste projeto, que foi uma palestra focada em alunas de Computação proferida por uma gestora de recursos humanos;

- as alunas da Graduação instituíram um grupo de contatos no WhatsApp para viabilizar a interação entre elas.

\subsection{Palestra sobre o Mercado de Tecnologia da Informação (TI) e Mulheres na Computação}

A palestra sobre o mercado de TI e mulheres na Computação foi realizada por uma gestora experiente de recursos humanos de uma empresa de Tecnologia de Informação. A palestra abordou aspectos como: formas de elaborar um currículo; o que se deve colocar no currículo quando não se tem experiência profissional prévia; como se comportar em uma entrevista de emprego; o que o mercado espera do profissional do ponto de vista técnico e interpessoal; a importância das informações postadas nas redes sociais dos candidatos a uma vaga de emprego; o cuidado com a escrita correta ao contatar uma empresa.

Os questionamentos realizados pelas alunas foram dentro dos seguinte aspectos: diferença salarial entre mulheres e homens no mercado de trabalho; como lidar com situações de machismo no ambiente corporativo; dificuldade para mulheres chegarem a cargos de gestão; visão do mercado sobre os cursos e profissionais da instituição em que elas estudam; aspectos técnicos das vagas em aberto no mercado de trabalho.

\subsection{Roda de Conversa sobre Questões de Gênero}

A roda de conversa sobre questões de gênero foi realizada por profissionais da equipe de Psicologia e Assistência Social da instituição: duas psicólogas, duas assistentes sociais e uma técnica em assuntos educacionais. A roda de conversa envolveu somente alunas do curso técnico. Optou-se por não realizar a atividade com as alunas da graduação e do técnico em conjunto por que elas estão passando por momentos diferentes da vida: um grupo passa pela adolescência, enquanto outro está no início da fase adulta. Com isso, devido à temática da roda de conversa, as alunas adolescentes poderiam se sentir inibidas para colocarem seus pensamentos e dúvidas diante de um grupo maior e com mulheres em início da fase adulta. Além disso, priorizou-se realizar a atividade com o 
grupo de alunas do curso técnico por que havia sido relatado à coordenadora do projeto a existência de problemas de relacionamento entre os alunos de uma das turmas do curso técnico referente a questões de gênero.

O objetivo da atividade foi, então, orientar e apoiar especificamente as alunas do curso técnico para lhes fornecer subsídios para lidar com situações de machismo e de violência contra a mulher, bem como criar um canal de comunicação entre elas, o setor de Psicologia e Assistência Social e as professoras de Computação da instituição. Esse tipo de trabalho não havia sido realizado na instituição até então.

A atividade foi realizada pelas profissionais em duas tardes, da seguinte forma: (1) inicialmente, elas apresentaram um histórico da mulher na sociedade, evidenciando as origens do que se chama de sociedade patriarcal; (2) foi realizada uma dinâmica com as alunas na qual elas puderam expor e discutir suas percepções sobre como os papeis da mulher e do homem são vistos na sociedade atual, bem como suas principais dificuldades e receios em relação ao mercado de trabalho; (3) no segundo dia, foi realizada uma discussão sobre os tipos de violência contra a mulher.

A experiência dessa roda de conversa foi muito rica e proveitosa, de forma que a equipe de Psicologia e Assistência Social da instituição planeja replicá-la periodicamente com as alunas da instituição de forma global.

\section{Lições Aprendidas}

A principal particularidade deste projeto é que as ações lidam com alunas de dois níveis de ensino e que, portanto, atravessam momentos diferentes e vivenciam experiências escolares também diferentes. Com as atividades do projeto realizadas até o momento, foi possível perceber que algumas atividades podem ser perfeitamente realizadas com as alunas em conjunto, desde que se atente para tratar das questões de interesse de ambos grupos, como foi o caso do primeiro encontro e da palestra realizadas no projeto. Por outro lado, há atividades que devem ser realizadas para o grupo específico, como foi o caso da roda de conversa, devido à temática abordada: questões de gênero e violência sexual.

Durante a roda de conversa, as alunas pontuaram questões que são específicas do momento pelo qual estão passando, a adolescência. É possível que se estivessem em um grupo maior com mulheres adultas, não se sentissem à vontade para colocar suas questões, o que poderia prejudicar a atividade. Outro ponto a ser destacado é que a participação ou pelo menos a orientação de um profissional de atuação psicopedagógica pode ser essencial para o sucesso de uma atividade, a depender da sua natureza, especialmente quando questões relacionadas à gênero, como machismo e violência, são levantadas.

O cuidado para tornar o ambiente das atividades confortável e receptivo para as alunas também é importante. Por exemplo, em todas as atividades realizadas, as professoras preparam uma lanche simples para as participantes; percebeu-se que essa ação contribuiu para aderência das alunas à atividade e para a interação entre elas. 


\section{Considerações Finais}

Este trabalho descreve um projeto voltado para alunas de dois cursos técnicos e de um curso de graduação em Computação do CEFET-MG. O projeto visa por objetivo incentivá-las e apoiá-las a concluírem seus cursos, bem como encorajá-las para o mercado de trabalho. O principal desafio neste tipo de iniciativa é abordar as atividades de forma adequada aos dois grupos de estudantes: um formado por adolescentes e outro por mulheres no início da fase adulta. É apresentado um relato de experiências a partir das ações que já foram realizadas no âmbito deste projeto.

Um problema importante que pode ser amenizado neste projeto é a evasão das alunas em cursos de Computação na instituição. O presente projeto tem duas formas de contribuir para a solução deste problema. A primeira é que as participantes do projeto, como bolsistas, sentir-se-ão naturalmente incentivadas com as atividades que desempenharão no projeto, sejam atividades técnicas ou de organização dos eventos. A segunda é que o projeto envolve atividades destinadas ao apoio de alunas que já cursam Computação. Ao apoiar as alunas dos cursos, esse projeto poderá motivá-las a persistir e concluir o curso, bem como atuar nessa área de formação, apesar das barreiras e dificuldades encontradas.

De forma complementar, a longo prazo, o projeto pode contribuir também para desmistificar a ideia de que a computação é uma área masculina e, por isto, motivar novas entrantes na área. Como resultado, espera-se criar e consolidar uma rede de apoio mútuo entre as alunas desses cursos, bem como um grupo de orientação a elas, com atividades sistemáticas supervisionadas pelas professoras.

\section{Referências}

Beaubouef, T. e Zhang, W. (2011). Where Are The Women Computer Science Students?. J. Comput. Sci. Coll. 26, 4 (April 2011), 14-20.

Cohoon, J. M. e Aspray, W. (2006). Women and Information Technology: Research On Underrepresentation, Vol. 1, 1 Ed., The MIT Press.

Maia, M. M. (2016). Limites de gênero e presença feminina nos cursos superiores brasileiros do campo da computação. Cadernos Pagu, (46), 223-244

Matsu, C. (2017). Mulheres sempre foram protagonistas em computação. Disponível em: https://goo.gl/AJdwBM. Acesso em: 11/03/2019.

Organização das Nações Unidas (ONU). (2015). Programa das Nações Unidas para o esenvolvimento (PNUD). Objetivos do Desenvolvimento Sustentável. Disponível em: https://nacoesunidas.org/pos2015/ods5/. Acesso em: 11/03/2019.

Sales, A., Calado, B., Silva, D. R. D., Mattos, G. O. e Moreira, J. A. (2014). Dificuldades para o ingresso e permanência na ciência e engenharia da computação: um olhar feminino. $18^{\circ}$ REDOR, UFRPE. Recife, PE.

Santos, C. M. Por que as Mulheres "Desapareceram" dos Cursos de Computação?. Jornal da USP. Março de 2018. 